\title{
PEDIATRIC LUPUS NEPHRITIS: CLINICAL-LABORATORY AND PATHOLOGICAL PROFILE OF 32 PATIENTS
} IN THE AMAZON REGION

Matheus Diniz Araujo Teixeira (Universidade Federal do Amazonas, Manaus, AM, Brasil), Rosana Souza Barros (Universidade Federal do Amazonas, manaus, AM, Brasil), Camila Maria Paiva Franca Telles (Universidade Ferderal do Amazonas, Manaus, AM, Brasil)

\section{BACKGROUND}

Systemic Lupus Erythematosus(SLE) is a multisystemic autoimmune disease that shows a broad spectrum of clinical and immunological abnormalities. Lupus Nephritis(LN) presents a more abrupt onset and worse clinical course when present in the pediatric age, requiring greater medical care. The present study proposes to determine the clinical, histopathological(renal) and laboratory characteristics of children with LN.

\section{MATERIALS AND METHODS}

This is a retrospective observational study evaluating patients diagnosed with childhood-onset SLE(c-SLE) according to the SLICC criteria(2012) that were followed up from 2015 to 2019 in a pediatric rheumatology service in the state of Amazonas, and all informations were collected in the records of service.

\section{RESULTS}

Fifty patients with SLE were treated in the study period, 32 of them with NL. The mean age of onset of the disease was $12.43( \pm 2.53)$ years, mean follow-up time was $2.69( \pm 1.71)$ years and mean duration of disease was $2.93( \pm 1.69)$ years. Twenty-nine(90.62\%) children were female and, in relation to the ethnic distribution,"browns" accounted for $93.75 \%$ and two(6.25\%) were indians. About one-third had a family history of SLE. Seventeen(53.12\%) had onset of NL that the first manifestation of C-SLE and the mean time of onset of NL after diagnosis of SLE was $7.09 \pm 13.14$ months for all patients. At the time of diagnosis, ANA and anti-dsDNA were positive in most patients ( $100 \%$ and 62.5 respectively), as well as low C3 and/or C4 were observed frequently $(59.37 \%)$. Six(18.75\%) presented reactive anti-cardiolipin in moderate titers and only four(12.5\%) presented anti-Sm positive. The mean markers of renal function at diagnosis were: urea 51.09( \pm 53.82 ); creatinine $1.20( \pm 1.68)$; proteinuria 24 hours $1261.96( \pm 1535.87)$ grams. Fifty $(46.87 \%)$ were submitted to renal biopsy, resulting in the following histological classes (2018 ISN/RPS): I(3.12\%); II(3.12\%); III(3.12\%); IV(31.27\%); V(3.12\%) and VI(3.12\%). In the scope of the assessment of permanent damage index(SLICC/ACR-DI): neuropsychiatric(34.37\%), cutaneous(25\%), renal(25\%) and musculoskeletal(18.75\%). SLEDAl at the time of diagnosis revealed a mean of $20.71 \pm 10.79$ and, after approximately 2.5 years of follow-up, mean of SLEDAI was $17.35 \pm 10.46$. Correlation in dialysis between the LN patients at the beginning of the C-SLE vs non-LN at the beginning of c-SLE was significant $(29.41 \%$ vs $0 \%, p=0.0109$ ), showed that the first group had more individuals than need dialysis therapy. Four patients died, being active disease and severe infection the causes of death.

\section{CONCLUSION}

It was verified in this study that children with LN have high rates of disease activity at diagnosis, with greater risk of needing dialysis therapy those who presented NL to the diagnosis. 